\title{
ESTUDO DO POTENCIAL ENERGÉTICO DE BRIQUETES PRODUZIDOS A PARTIR DE RESÍDUOS DA CASCA DE COCO VERDE E BAGAÇO DE CANA
}

João Marcos Martins Bezerra - joaomarcosmartins@ hotmail.com Universidade Federal do Ceará

Mariana de Souza Vidal - marianavidal.18@ hotmail.com

Universidade Federal do Ceará

Deiby Anne Uchôa Barroso Bizerra - deiby_anne@hotmail.com

Universidade Federal do Ceará

Jackson de Queiroz Malveira - jackson.malveira@ nutec.ce.gov.br

Fundação Núcleo de Tecnologia Industrial do Ceará

Maria Alexsandra de Sousa Rios (ORIENTADORA) - alexsandrarios@ufc.br

Universidade Federal do Ceará 


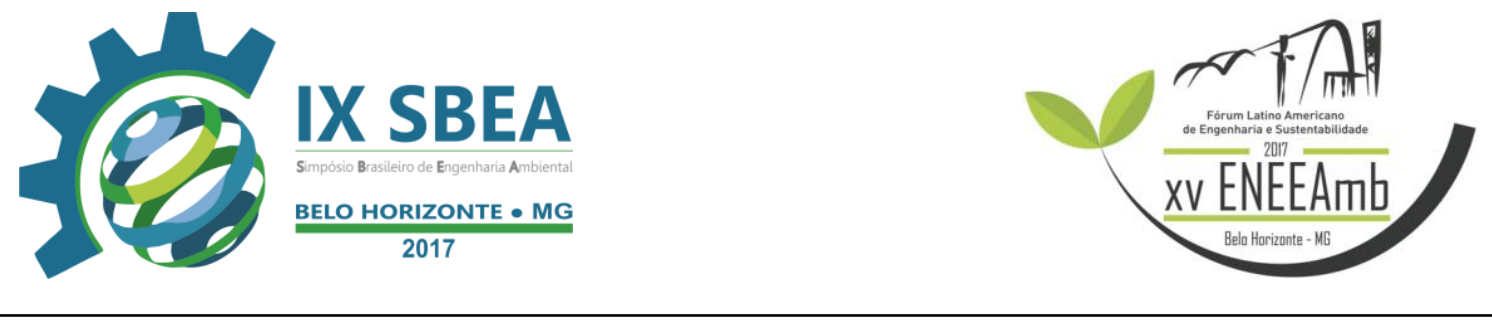

\section{RESUMO}

O Brasil é um grande gerador de resíduos provenientes da casca de coco verde e bagaço de cana. Esses dois tipos de resíduos sólidos ocupam um espaço considerável nos aterros sanitários e ainda podem causar sérios problemas ambientais, quando negligenciados e deixados de forma incorreta na natureza. Neste contexto, o presente trabalho teve por finalidade estudar o potencial energético dos briquetes produzidos a partir da mistura da casca do coco verde e do bagaço de cana. Os briquetes produzidos com estes resíduos surgem como uma alternativa, para fornecimento de energia, no qual é capaz de substituir com eficiência fontes de energia advindas dos combustíveis fósseis que contribuem, significantemente, para o aumento do efeito estufa no planeta. O estudo em questão investigou os briquetes produzidos a partir das proporções 0/100, 25/75, 50/50, 75/25 e 100/0 para casca de coco/bagaço de cana. De acordo com os resultados, o briquete feito com $100 \%$ da casca de coco apresentou o melhor potencial energético $(16,495 \mathrm{MJ} / \mathrm{kg})$, pois para um mesmo teor de umidade de $10,89 \%$, este apresentou o poder calorífico mais elevado.

Palavras-chave: Briquetes, Potencial energético, Casca de coco, Bagaço de cana.

\section{INTRODUÇÃO/OBJETIVO}

$\mathrm{Na}$ atualidade, os problemas com as questões energéticas têm sido alvo de preocupação em grande parte do mundo, pois a maior parte da matriz energética mundial utiliza combustíveis fósseis para geração de energia. É neste contexto, que surge uma nova fonte geradora de energia: a biomassa. A utilização da biomassa como fonte geradora de energia surge como uma possível solução para os problemas energéticos e ambientais enfrentados no mundo, já que é uma fonte de energia limpa e renovável, que pode ser formada a partir de resíduos sólidos, antes desperdiçados na natureza em forma de lixo (ANEEL, 2016; ALVES JR. e SANTOS, 2002).

No Brasil, uma das principais fontes de energia com maior potencial de desenvolvimento nos próximos anos é a biomassa, que traz vantagens na atenuação da dependência de combustíveis fósseis e na diversificação da matriz energética do país. Apesar de ser encontrada em maior abundância, grande parte destes recursos 
energéticos encontra-se em regiões pouco desenvolvidas, na qual têm como principal fonte de subsistência a agricultura (ANEEL, 2016).

A matriz energética brasileira ainda é muito dependente dos combustíveis fósseis, fato este que implica diretamente no incremento da poluição e consequente aumento dos problemas ambientais, assim como, o aumento do quantitativo de resíduos industriais e urbanos, além de subutilizar uma especial fonte de energia renovável que é a biomassa presente nos referidos resíduos.

Em se tratando da biomassa presente nos resíduos sólidos, a casca de coco e o bagaço da cana representam grande parte do lixo gerado nos grandes centros urbanos do Brasil. Estima-se que, $80 \%$ do lixo gerado no litoral dos grandes centros urbanos brasileiros seja composto pela casca de coco. Esse resíduo tem grande potencial para se tornar importante matéria-prima para biocombustível, agregar valor e diversificar a matriz energética nordestina (BITENCOURT e PEDROTTI, 2008).

Já o bagaço da cana, é o maior resíduo agrícola produzido no Brasil com aproximadamente $280 \mathrm{~kg}$ de bagaço por tonelada de cana-de-açúcar moída (KOHLHEPP, 2010). Esses tipos de resíduos lignocelulósicos possuem uma relevante capacidade calorífica, como também são fontes energéticas capazes de substituir algumas fontes de combustíveis fósseis, o que pode tornar essa atividade vantajosa (SILVA et al., 2007).

Uma forma de aproveitamento desses resíduos é a utilização destes como briquetes. Briquetes são blocos densos e compactos que podem ser formados com diversos tipos de resíduos sólidos. O processo de briquetagem consiste na compactação dos resíduos no qual, esta compactação têm a função de destruir a elasticidade natural do material a ser utilizado (BIOMAX, 2016); esse processo provoca a aglomeração das partículas, formando uma espécie de junção de lignina (SILVEIRA, 2008). Sua formação se dá pela alta pressão ou pela alta temperatura. Sem a destruição da elasticidade natural, os briquetes se tornam não duráveis (BIOMAX, 2016).

Diante desse cenário, o presente trabalho foi desenvolvido visando o estudo e aproveitamento destes dois tipos de resíduos que, de certa forma, quando expostos de maneira incorreta no ambiente trazem inúmeros malefícios a população. O estudo desenvolvido envolveu análises necessárias a qualificação dos materiais, como uma boa 
alternativa para aproveitamento destes como fonte geradora de energia. Tais análises foram: Teor de Umidade, Teor de Voláteis, Teor de Cinzas, Carbono Fixo e Poder Calorífico Superior (PCS).

\section{METODOLOGIA}

Os experimentos foram realizados no Laboratório de Referência em Biocombustíveis Prof. Expedito José de Sá Parente (LARBIO), localizado no Núcleo de Tecnologia Industrial do Ceará - NUTEC, Fortaleza - CE.

\subsection{Coleta das Amostras}

Para este trabalho foram utilizadas amostras da casca de coco verde triturada, Figura 1(a) e amostras de bagaço de cana, Figura 1(b).
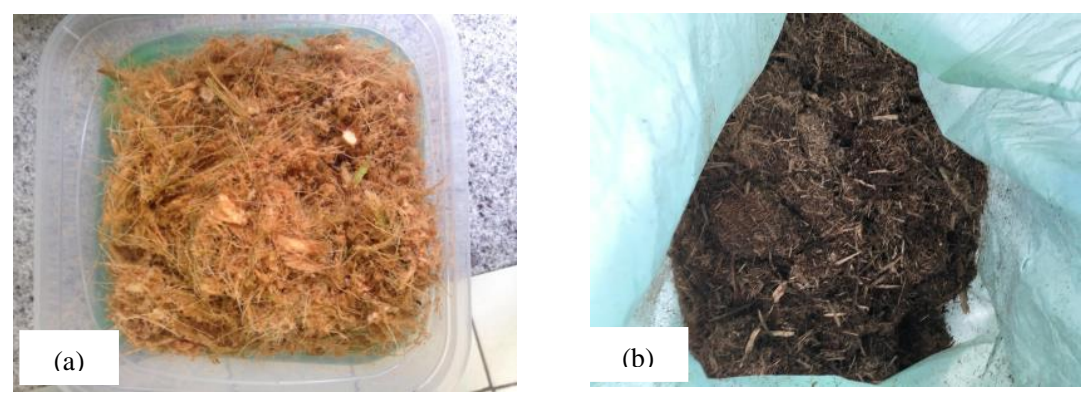

Figura 1 - Matéria-prima: (a) Casca de coco verde; (b) Bagaço de cana Fonte: Autores.

As amostras foram levadas ao LARBIO, onde foram caracterizadas através das análises de determinação do teor de umidade (ABNT NBR 14929), Poder Calorífico Superior (DIN EN 14918:2014), teor de cinzas (ABNT NBR 13999 e ASTM D3174), carbono fixo (ASTM D3172) e teor de voláteis (ABNT NBR 8112 e ASTM D3175). Todos os experimentos foram realizados em duplicata.

\section{RESULTADOS E DISCUSSÃO}

Os resultados das análises imediatas foram obtidos por meio das determinações dos teores de umidade, materiais voláteis, carbono fixo e cinzas. Os resultados estão apresentados na Tabela 1. 


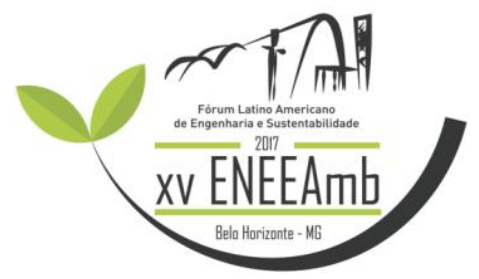

Tabela 1 - Análise imediata dos briquetes de casca de coco/bagaço de cana

\begin{tabular}{l|c|c|c|c}
\hline \multicolumn{1}{c|}{ Amostras } & $\begin{array}{c}\text { Umidade } \\
(\boldsymbol{\%})\end{array}$ & $\begin{array}{c}\text { Voláteis } \\
(\boldsymbol{\%})\end{array}$ & $\begin{array}{c}\text { Cinzas } \\
\mathbf{( \% )}\end{array}$ & $\begin{array}{c}\text { Carbono fixo } \\
\mathbf{( \% )}\end{array}$ \\
\hline BRIQUETE (100\% COCO) & 10,89 & 77,84 & 3,2 & 8,07 \\
\hline BRIQUETE (100\% CANA) & 11,35 & 75,76 & 6,8 & 6,09 \\
\hline BRIQUETE (50\% COCO/50\% CANA) & 11,12 & 79,56 & 4,8 & 4,52 \\
\hline BRIQUETE (75\% COCO/25\% CANA) & 10,99 & 78,96 & 3,7 & 6,35 \\
\hline BRIQUETE (25\% COCO/75\% CANA) & 11,23 & 79,09 & 6,6 & 3,08 \\
\hline
\end{tabular}

Fonte: Autores.

\subsection{Análise das Matérias-Primas e dos Briquetes}

\subsubsection{Teor de umidade}

Os teores de umidade em base úmida foram determinados para cada matériaprima. Os valores encontrados foram de $88,22 \%$ para a casca de coco verde in natura e de $65,07 \%$ para o bagaço da cana. Sabe-se que o teor de umidade influencia negativamente no valor do Poder Calorífico, sendo, portanto, importante que o briquete não tenha uma umidade elevada. As matérias-primas foram secas em estufa $\left(105^{\circ} \mathrm{C}\right)$ até atingirem uma umidade de $10,89 \%$ para a casca do coco e $11,35 \%$ para o bagaço da cana.

\subsubsection{Teor de voláteis}

Os teores de voláteis foram encontrados para cada matéria-prima e para os briquetes. Os teores de voláteis para casca de coco foi de $80,73 \%$ e $81,36 \%$ para o bagaço da cana. Os materiais voláteis queimam e saem rapidamente na forma gasosa. Segundo Vieira (2012), a biomassa com alto teor de voláteis apresenta maior facilidade de queimar.

\subsubsection{Teor de cinzas}

O teor de cinzas para as matérias-primas foi de $0,55 \%$ para a casca de coco e de 2,66\% para o bagaço da cana. Segundo Vieira et al. (2013), um alto teor de cinzas leva a uma diminuição da eficiência devido ao aumento do consumo de oxigênio para derreter as cinzas. Como a umidade, o teor de cinzas também interfere no poder 
calorífico causando perda de energia, além de prejudicar a transferência de calor (KLAUTAU, 2008). Valores elevados de cinzas além de influenciarem negativamente o poder calorífico, podem muitas vezes, em determinados processos de combustão, obrigar a parada da produção de energia para a retirada das cinzas.

\subsubsection{Teor de carbono fixo}

Os teores de carbono fixo encontrados foram de 8,07\% para o briquete feito com $100 \%$ da casca de coco; 6,09\% para o briquete feito com $100 \%$ de bagaço da cana; $4,52 \%$ para o briquete feito com $50 \%$ de bagaço de cana e $50 \%$ de casca de coco; $6,35 \%$ para o briquete feito com $75 \%$ de casca de coco e $25 \%$ de bagaço de cana e 3,08\% para o briquete feito com $75 \%$ de bagaço de cana e $25 \%$ de casca de coco. O carbono fixo pode ser definido como a quantidade de carbono presente na biomassa após a retirada da umidade, cinzas e voláteis. O carbono fixo queima lentamente na fase sólida. Combustíveis com alto índice de carbono fixo apresentam queima mais lenta, resultando assim, em um maior tempo de residência nos equipamentos de queima, em comparação a outros combustíveis com menor teor de carbono fixo (VALE e GENTIL, 2008). Segundo (QUIRINO, 1991), o rendimento em carbono fixo de um material é o parâmetro que melhor expressa à qualidade da matéria-prima lignocelulósica, para a produção de carvão vegetal.

\subsubsection{Poder Calorífico Superior (PCS)}

Os PCS's para a casca de coco e bagaço da cana, após secagem em estufa $\left(105{ }^{\circ} \mathrm{C}\right)$, foram de $16,567 \mathrm{MJ} / \mathrm{kg}$ e $18,675 \mathrm{MJ} / \mathrm{kg}$, respectivamente. Com uma umidade de $11,35 \%$ e $10,89 \%$ o PCS para o bagaço de cana e casca de coco foram de $14,554 \mathrm{MJ} / \mathrm{kg}$ e 10,157 MJ/kg, respectivamente. In natura, o bagaço da cana apresentou PCS de 7,675 MJ/kg, enquanto que a casca de coco verde não iniciou combustão. Os PCS's para os briquetes foram de $16,495 \mathrm{MJ} / \mathrm{kg}$ para o briquete feito com $100 \%$ da casca de coco; 15,868 MJ/kg para o briquete feito com $100 \%$ de bagaço da cana; $16,236 \mathrm{MJ} / \mathrm{kg}$ para o briquete feito com $50 \%$ de bagaço de cana e $50 \%$ de casca de coco; $15,201 \mathrm{MJ} / \mathrm{kg}$ para o briquete feito com $75 \%$ de casca de coco e $25 \%$ de bagaço 
de cana e $16,295 \mathrm{MJ} / \mathrm{kg}$ para o briquete feito com $75 \%$ de bagaço de cana e $25 \%$ de casca de coco.

Segundo Quirino (1991), o poder calorífico é a quantidade de calorias liberada por um material em sua combustão completa, dado normalmente em $\mathrm{MJ} / \mathrm{kg}$ para os combustíveis sólidos, $\mathrm{MJ} / \mathrm{L}$ para combustíveis líquidos e em $\mathrm{MJ} / \mathrm{m}^{3}$ para os combustíveis gasosos. O poder calorífico é um parâmetro que mede a eficiência energética e serve como importante indicador, para se conhecer a capacidade calorífica de uma determinada espécie. Os valores de PCS encontrados mostraram-se bastante promissores quando comparados aos valores de outros tipos de biomassa citados na literatura, como por exemplo: casca de arroz 16,108 $\mathrm{MJ} / \mathrm{kg}$ e bagaço de cana 16,673 MJ/kg (SILVA e MORAIS, 2008) e palha do milho com 15,606 MJ/kg (QUIRINO, 1991). Os resultados de PCS e teor de umidade podem ser verificados na Tabela 2.

Tabela 2 - Poder calorífico superior e teor de umidade

\begin{tabular}{l|c|c}
\hline \multicolumn{1}{c|}{ Amostras } & $\begin{array}{c}\text { Umidade } \\
(\boldsymbol{\%})\end{array}$ & $\begin{array}{c}\text { Poder Calorífico Superior } \\
(\mathbf{M J} / \mathbf{k g})\end{array}$ \\
\hline BRIQUETE (100\% COCO) & 10,89 & 16,495 \\
\hline BRIQUETE (100\% CANA) & 11,35 & 15,868 \\
\hline BRIQUETE (50\% COCO/50\% CANA) & 11,12 & 16,236 \\
\hline BRIQUETE (75\% COCO/25\% CANA) & 10,99 & 15,201 \\
\hline BRIQUETE (25\% COCO/75\% CANA) & 11,23 & 16,295 \\
\hline
\end{tabular}

Fonte: Autores.

Com base nos resultados de PCS apresentados na Tabela 2 e, fazendo uma comparação com os resultados do poder calorífico das biomassas anteriormente citadas, pode-se inferir que os briquetes produzidos com os resíduos da casca de coco verde e bagaço da cana possuem um significativo potencial energético. 




\section{CONCLUSÕES/RECOMENDAÇÕES}

A amostra do briquete produzido com $100 \%$ da casca de coco apresentou o menor teor de cinzas $(3,2 \%)$, o que a torna interessante para utilização como fonte energética em caldeiras e fornos industriais.

Os teores de voláteis foram de 77,84\% para o briquete de $100 \%$ da casca de coco $; 75,76 \%$ para o briquete de $100 \%$ de bagaço da cana; $79,56 \%$ para o briquete de $50 \%$ de bagaço de cana e $50 \%$ de casca de coco; $78,96 \%$ para o briquete de $75 \%$ de casca de coco e $25 \%$ de bagaço de cana e 79,09\% para o briquete de $75 \%$ de bagaço de cana e $25 \%$ de casca de coco, o que indica que as cinco amostras teriam a mesma facilidade para iniciar o processo de combustão.

O briquete feito com $100 \%$ da casca de coco apresentou um potencial energético melhor quando comparado aos demais briquetes, pois para um valor de umidade de 10,89\% foi obtido o PCS mais elevado.

De acordo com os resultados pode-se concluir que, as matérias-primas investigadas possuem significativo potencial energético e aplicabilidade como combustíveis sólidos quando comparadas a outras já existentes no mercado.

\section{REFERÊNCIAS BIBLIOGRÁFICAS}

ANEEL. Agência Nacional de Energia Elétrica. Biomassa. Home Page. Disponível em: <http://www.aneel.gov.br/aplicações/atlas/pdf/05-biomassa(2).pdf> Acesso em: 09 de jun. de 2016.

ALVES JUNIOR, F. T.; SANTOS, G. A. - Potencial de geração de biomassa para a briquetagem e o perfil do mercado consumidor deste insumo na região do Cariri-CE. In: II Congresso Ibero-Americano de Pesquisa e Desenvolvimento de Produtos Florestais \& Seminário em Tecnologia de Madeiras e Produtos Florestais não madeiráveis. Anais...Curitiba: FUPEF, p. 3. 2002.

BITENCOURT, D. V.; PEDROTTI, A. Usos da casca de coco: Estudo das viabilidades de implantação de usina de beneficiamento de fibra de coco em Sergipe. Revista da Fapese, v. 4, n. 2, p. 113-122, 2008. 
KOHLHEPP, G. Análise da situação da produção de etanol e biodiesel no Brasil. Estudos avançados, v. 24, n. 68, p. 223-253,2010.

SILVA, V. L. M..M.; GOMES, W. C.; ALSINA, O. L. S. Utilização do bagaço de cana de açúcar como biomassa adsorvente na adsorção de poluentes orgânicos. Campina Grande - PB., 2007, 6 p. Revista UEPB.

BIOMAX Indústria de máquinas LTDA - Disponível em: <http://www.biomaxind.com.br/site/br/briquetagem.html >. Acesso em: 2 de jul. 2016.

SILVEIRA, M. S. Aproveitamento das cascas de coco verde para produção de briquete em Salvador - BA. Bahia, 163 p., 2008. Dissertação (Mestrado em Gerenciamento e Tecnologias Ambientais no Processo Produtivo) - Universidade Federal da Bahia.

VIEIRA A. C.; Caracterização da biomassa proveniente de resíduos agrícolas. Paraná, 56 p., 2012. Dissertação (Mestrado) - Universidade Estadual do Oeste do Paraná.

KLAUTAU, V. P. Análise experimental de uma fornalha a lenha de fluxo de corrente para a secagem de grãos. Curitiba, 28 p., 2008. Dissertação (Mestrado em engenharia de recursos hídricos e ambiental) - Universidade Federal do Paraná.

VALE, A.T.; GENTIL, L.V. Produção e uso energético de biomassa e resíduos agroflorestais. Tecnologias aplicadas ao setor madeireiro III. Rio Branco: Suprema, p.195-241, 2008.

QUIRINO, W. F. Características de Briquetes de Carvão Vegetal a seu Comportamento na Combustão. Piracicaba, 80 p., 1991. Dissertação (Mestrado da Escola Superior Luiz de Queiroz) - Universidade de São Paulo. Piracicaba 
SILVA, M. B.; MORAIS, A. S. Avaliação Energética do Bagaço de Cana em Diferentes Níveis de Umidade e Graus de Compactação. In: XXVIII ENCONTRO NACIONAL DE ENGENHARIA DE PRODUÇÃO, Rio de Janeiro. Anais... Rio de Janeiro: ENEGEP, 2008, p. 1-9. 